\title{
Neurogenic muscular atrophy and low density of large myelinated fibres of sural nerve in chorea-acanthocytosis
}

\author{
A OH ISHI, Y SATO, H NAGARA, T SAKAI, \\ H I W ASH ITA, Y KUROIWA, T NAKAMURA, A N D SHIDA \\ From the Departments of Neuropathology and Neurology, Neurological Institute, \\ Faculty of Medicine, Kyushu University, Fukuoka; and the Department of Neurology, \\ Ohmuta Rosai Hospital, Ohmuta, Japan
}

S U M MARY In three cases of chorea-acanthocytosis (acanthocytosis and neurological disease, or familial degeneration of the basal ganglia with acanthocytosis), biopsies of short peroneal muscles and sural nerves were studied histologically. The muscles showed groups of atrophic fibres with clumping of sarcolemmal nuclei in all cases. It was concluded that neurogenic muscular atrophy should be included as one of the main pathological findings in choreaacanthocytosis. The sural nerves showed a small number of large myelinated fibres in two cases. This finding remains to be confirmed in other cases.

Chorea-acanthocytosis (acanthocytosis and neurological disease, or familial degeneration of the basal ganglia with acanthocytosis) ${ }^{1-9}$ is characterised by involuntary oro-linguo-facial and limb movements, acanthocytosis, decreased or absent deep tendon reflexes and muscular atrophy in the lower limbs. Although the muscular atropny is considered to be of neurogenic origin, ${ }^{35^{-7}} 9$ the serum creatine phosphokinase (CPK) level is higher than that usually seen in neurogenic muscular atrophy, suggesting the presence of a myopathic process in the muscular atrophy of this disease. On the other hand sensory disturbances with slight or moderate degree are noted in some cases. Pathological studies of sural nerve biopsy in this illness have been performed without adequate controls and quantification. ${ }^{5810}$ In this communication histopathological findings of biopsied short peroneal muscles and sural nerves above the ankle in three cases of choreaacanthocytosis $^{911}$ are presented and discussed.

Address for reprint requests: Dr A Ohnishi, Dept of Neuropathology, Neurological Institute, Kyushu University, Fukuoka 812, Japan. Accepted 10 March 1981

\section{Case reports}

Case 1 A 38-year-old female developed grimacing and lip-smacking when aged 29 years. Choreiform movements of both limbs and tongue biting gradually developed at age 35 years. A generalised convulsion was observed at age 38 years. On admission she was of average build; there were signs of tongue biting. Examination showed oro-linguo-facial dyskinesia and mild choreiform movements of both limbs. Her intelligence was within normal limits and her cranial nerves, motor function and deep tendon reflexes were all normal. Sensory system was normal except for mildly decreased vibration sensation in the lower limbs. Peripheral blood smear showed about $30 \%$ to $80 \%$ acanthocytes which were confirmed with scanning electron microscopy. Serum creatine phosphokinase value was 130 to $1000 \mathrm{mU} / \mathrm{ml}$ (normal 30 to $50 \mathrm{mU} / \mathrm{ml}$ ). Atrophy of the caudate nuclei was shown on computed tomography. On electromyography, giant potentials were found and the number of motor unit potentials during contraction (interference pattern) was moderately reduced in the right anterior tibial muscle. Sural nerve conduction study showed that the peak latency was $4.5 \mathrm{~ms}$ (control $<4 \cdot 1$ ) and the amplitude was $6.6 \mu \mathrm{V}$ (control $>6.0$ ). Four of nine siblings born from healthy but con- 
sanguineous parents had a similar neurological disorder presenting in the late twenties. Acanthocytosis was confirmed in three of them, one of whom is the second case in this report.

Case 2 A 33-year-old male developed gradually grimacing, lip smacking and tongue biting at 27 years. Choreiform movements of both limbs developed when aged 28 years and progressively increased thereafter. Right nucleus ventro-oralis posterior thalamotomy at the age of 29 years and a similar left thalamotomy at the age of 30 years markedly reduced the choreiform movements of both limbs and the oro-linguofacial movements. On examination he showed occasional dystonic movements of the trunk especially during conversation but these were almost absent at rest. He showed a wide-based and unsteady gait and often experienced sudden buckling of the trunk, almost falling down, but without injury. He had mild personality change and his intelligence had deteriorated mildly. Muscle tone was markedly decreased in all limbs. Coordination was moderately impaired and deep tendon reflexes were absent. There was a moderate degree of muscle atrophy in the lower limbs without weakness. Dysphagia and dysarthria with a voice of low volume were noted. Sensory examination was normal. Peripheral blood smear showed about $50 \%$ to $80 \%$ acanthocytes. Serum creatine phosphokinase value was $170 \mathrm{mU} / \mathrm{ml}$. On computed tomography atrophy of the caudate nuclei was shown. On electromyography the number of motor unit potentials during contraction was moderately decreased in the anterior tibial muscles. On sural nerve conduction study the peak latency was $3 \cdot 3 \mathrm{~ms}$ (control $<4 \cdot 1$ ) and the amplitude was $4 \cdot 3 \mu \mathrm{V}$ (control $>6.0$ ).

Case 3 A 37-year-old male noted involuntary movements of both limbs when aged 29 years. He gradually developed involuntary movements of trunk and tongue biting when aged 34 years. On admission he was of average build. The tongue was scarred from many bites. Examination showed oro-linguo-facial dyskinesia, dystonic neck movement, and mild choreiform movement of both limbs. There were mild changes in his personality, but his intelligence was normal. Cranial nerves and motor function were normal. In the lower limbs deep tendon reflexes were decreased and there was a moderate degree of muscle atrophy. Sensory examination was normal. Peripheral blood smear showed $12 \%$ to $19 \%$ acanthocytes. Serum creatinine phosphokinase value was $131 \mathrm{mU} / \mathrm{ml}$. On computed tomography atrophy of the caudate nuclei was revealed. There was no family history of a similar neurological disorder.

\section{Materials and methods}

In three cases combined fascicular sural nerve and peroneal muscle biopsy ${ }^{12}$ was performed $5 \mathrm{~cm}$ above the right lateral malleolus. The muscle specimen was frozen immediately after removal in isopentane cooled to $-80^{\circ} \mathrm{C}$ by dry ice, for enzyme histochemical studies. Cryostat sections were stained for diphos- phopyridine nucleotide (DPNH) dehydrogenase, myofibrillar adenosine triphosphatase (ATPase, pH 9.8, $4 \cdot 6,4 \cdot 3)$ and acid phosphatase. Other fresh-frozen sections were stained with haematoxylin and eosin, Sudan III and modified Gomori and were used for the demonstration of periodic acid-Schiff (PAS) reactive substances. One portion of the sural nerve was processed for teased fibre preparations. ${ }^{13}$ The other portion was processed for light and electron microscopy of Epon-embedded sections. Photographic enlargements $(\times 1000)$ of transverse epoxy sections were used to obtain the density (number per $\mathrm{mm}^{2}$ of fascicular area of total, large (diameter $>5 \mu \mathrm{m}$ ) and small (diameter $\leqslant 5 \mu \mathrm{m}$ ) myelinated fibres and their frequency distribution. In order to obtain the density and size frequency distributions of unmyelinated fibres, electronmicrographs $(\times 7500)$ were used. ${ }^{13} 14$ The findings in control sural nerves from patients without neurological signs and symptoms have been reported elsewhere. ${ }^{14} 15$

\section{Results}

Biopsy of a right short peroneal muscle in three cases showed pathological changes of similar character. There were small groups of atrophic fibres (5 to $15 \mu \mathrm{m}$ in diameter) with clumping of sarcolemmal nuclei distributed at random in all cases (fig). Large groups of atrophic fibres and hypertrophic fibres (150 to $180 \mu \mathrm{m}$ in diameter) were of ten observed only in case 2 . In all cases both normal and atrophic fibres belonging to both types I and II were found. Target fibres were prominent in type I fibres in case 3 . The frequencies of central nuclei were $12 \%, 12 \%$ and $10.5 \%$ in cases 1,2 and 3 respectively.

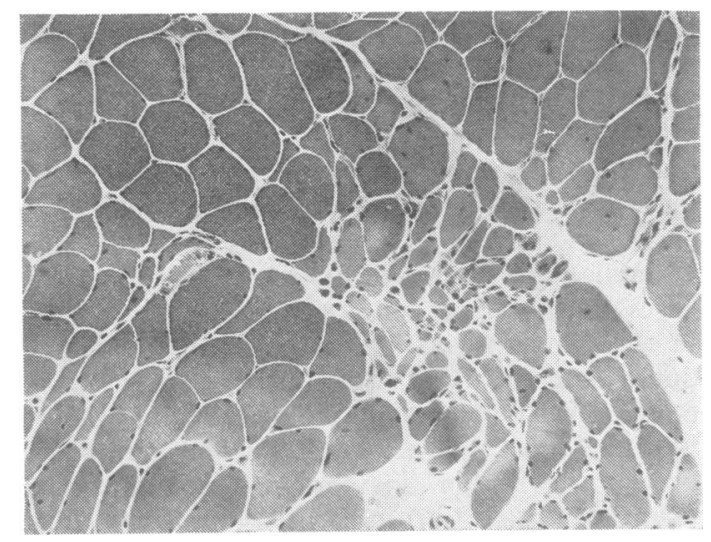

Figure Transverse section of the short peroneal muscle in case 3 ( $H$ and $E$ staining). Note groups of atrophic fibres and small angulated fibres scattered at random $(\times 120)$. 
Table Histopathological findings of sural nerve

\begin{tabular}{lrrrrr}
\hline & \multicolumn{2}{c}{ Myelinated fibres } & & Fibre densities* & $\begin{array}{l}\text { Teased fibre } \\
\text { abnormality! }\end{array}$ \\
\cline { 2 - 5 } & total & large & small & & \\
\hline Case 1 & 7,185 & 2,802 & 4,383 & 39,894 & $3 \%$ \\
Case 2 & 9,316 & 3,144 & 6,172 & 29,794 & $8 \%$ \\
Case 3 & 7,949 & 2,560 & 5,389 & 33,813 & $1 \%$ \\
Control Mean & 10,229 & 4,503 & 5,726 & 34,470 & $<10 \%$ \\
$\quad$ Standard error & 496 & 377 & 300 & 3,753 & \\
\hline
\end{tabular}

* Number $/ \mathrm{mm}^{2}$ of fascicular area

$\dagger$ Frequency of abnormal myelinated fibre

Quantitative histopathological findings of the sural nerve are shown in the table. The frequency of teased myelinated fibres showing abnormalities was within normal limits in each case. ${ }^{1415}$ The density (number per $\mathrm{mm}^{2}$ of fascicular area) of total myelinated fibres was slightly decreased in cases 1 and 3, and it was ascribed to the decrease of the density of large myelinated fibres in both cases. ${ }^{1415}$ The density of unmyelinated fibres was within normal limits. ${ }^{14}$ In case 1 the swelling of an unmyelinated axon filled with glycogen granules (beta particle) was found, but it was not observed in the other two cases. No abnormal inclusion bodies were found in the cytoplasm of Schwann cells, fibroblasts, perineurial cells, and endothelial and perithelial cells of small vessels.

\section{Discussion}

Histological changes in the short peroneal muscles were similar in the three cases and are compatible with chronic neurogenic muscular atrophy ${ }^{16}$ and with the findings reported previously in this disease. ${ }^{3-7} 9$ There was nothing to suggest primary muscular degeneration. The reason why the CPK level was markedly elevated in the face of the neurogenic muscular atrophy remains unknown.

Although vibration sensation is reported to be decreased in about half the cases in the literature,,$^{359}$ the nature of the degeneration of sensory nerve fibres is not known. The loss of myelinated fibres is described in some cases, ${ }^{5810}$ however the patients were relatively old and the description does not give quantified data with adequate controls. In our systematic morphometric studies, a slight but definite decrease of the density of large myelinated fibres was found in two cases and this may be compatible with the decreased vibration sense in case 1 . On teased fibre analysis the frequency of myelinated fibres showing abnormalities was within normal limits in all cases. Therefore slowly progressive degeneration of large myelinated fibres, possibly of axonal type, may be assumed to exist in the sural nerve in this disease.

\section{References}

1 Estes JW, Morley TJ, Levine IM, Emerson CP. A new hereditary acanthocytosis syndrome. $\mathrm{Am} \mathrm{J}$ Med 1976; 42:868-81.

2 Critchley EMR, Clark DB, Wikler A. Acanthocytosis and neurological disorder without $\alpha$ betalipoproteinemia. Arch Neurol (Chicago) 1968; 18: $134-40$.

3 Levine IM, Estes JW, Looney JM. Hereditary neurological disease with acanthocytosis; A new syndrome. Arch Neurol (Chicago) 1968; 19:403-9.

4 Critchley EMR, Nicholson JT. Acanthocytosis, normolipoproteinemia and multiple tics. Postgrad Med J 1970; 46:698-701.

5 Aminoff MJ. Acanthocytosis and neurological disease. Brain 1972; 95:749-60.

6 Shimizu T, Inoue $K$, Sugita $H$, Nakanishi T, Toyokura Y. Self-mutilation, choreoacanthocytosis, muscular hypotonia, absence of deep tendon reflexes and normouricemia; Report of adult case. Neurol Med (Tokyo) 1974; 1:135-6.

7 Itoga E, Kito S, Tsubota W, et al. A case of amyotrophic chorea with acanthocytosis. Hiroshima J Med Sci 1978; 31:772-5.

8 Bird TD, Cederbaum S, Valpey RW, Stahl WL. Familial degeneration of the basal ganglia with acanthocytosis: A clinical, neuropathological, and neurochemical study. Ann Neurol 1978; 3:253-8.

9 Nagashima T, Iwashita H, Kuroiwa Y, Ohnishi A. Chorea-acanthocytosis; a report of a family. Clin Neurol (Tokyo) 1979;19:609-15.

10 Lantos PL, Aminoff MJ. Fine structural changes in the sural nerve of patients with acanthocytosis. Acta Neuropathol (Berlin) 1972; 22:257-63.

11 Sakai T, Muraoka S, Iwashita H, Sato Y, Ohnishi A, Nakamura T. Chorea-acanthocytosis. Clin Neurol (Tokyo) 1980; 20:1062-3.

12 Ohnishi A, Kumaki K. An improved method of combined sural nerve and peroneal muscle biopsy. Clin Neurol (Tokyo) 1972; 12:449-52.

13 Dyck PJ. Pathologic alterations of the peripheral nervous system of man. In: Dyck PJ, Thomas PK, Lambert EH, eds. Peripheral Neuropathy. Philadelphia: W B Saunders, 1975; vol 1: 296-336.

14 Ohnishi A, Tsuji S, Igisu H, Murai Y, Goto I, Kuroiwa $Y$, Tsujihata $M$, Takamori M. Beriberi neuropathy; Morphometric study of sural nerve. J Neurol Sci 1980; 45:177-90. 
15 Ohnishi A, Ikeda M, Tateishi J. Morphometry of myelinated fibres of sural nerve, $L_{5}$ spinal roots and fasciculus gracilis and of cytons of L5 spinal ganglion in man. Neurol Med (Tokyo) 1979; 11:160-8.
16 Drachman DB, Murphy SR, Nigam MP, Hills JR. "Myopathic" changes in chronically denervated muscle. Arch Neurol (Chicago) 1967; 16: 14-24. 